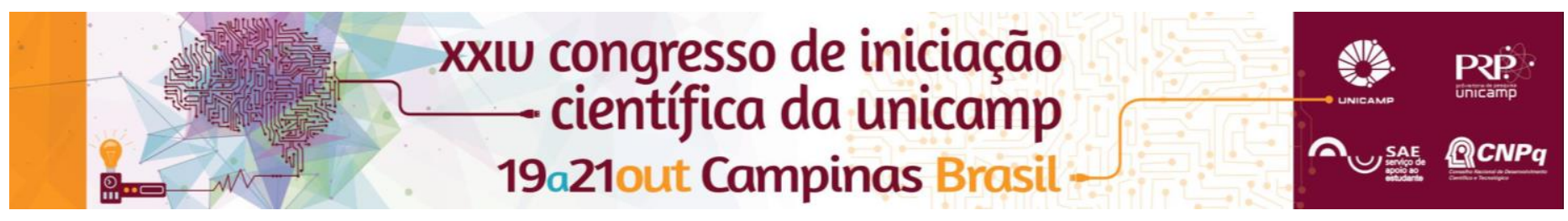

\title{
Conceitos matemáticos aplicados ao arduino utilizando tecnologia bluetooth
}

\author{
Renata de Oliveira*, Daniela S. Santana, Flavio Mania
}

\section{Resumo}

Esse projeto tem como objetivo proporcionar através do carro chassi o entendimento de conceitos da matemática, tais como distância entre dois pontos, inclinação da reta e plano de argand-gauss com a plataforma arduino uno utilizando a tecnologia bluetooth para comunicação.

\section{Palavras-chave:}

Arduino, bluetooth, Matemática.

\section{Introdução}

O Arduino, é um equipamento utilizado por ser de baixo custo e acessível ao seu público, permite ser aplicados a diversos projetos interdisciplinares, dando suporte e simplificando suas complexidades (Monk, 2014).

Com o carro chassi e a plataforma arduino uno utilizando módulo bluetooth. Foram aplicados os seguintes conceitos da matemática: plano Cartesiano, distância entre dois pontos, ponto médio e classificação da inclinação da reta e aritméticas do plano ArgandGauss.

\section{Resultados e Discussão}

Realizados os testes de funcionamento do carro chassi com a tecnologia bluetooth, o carro percorreu os planos: Argand-Gauss e Cartesiano.

Os conceitos estudados utilizando o carro chassi foram: inclinação da reta, distância entre dois pontos e plano de Argand-Gauss, que serão vistos a seguir:

Inclinação da reta, para a classificação da inclinação da reta será decrescente, crescente, constante ou inexistente geralmente a reta possui um nome por exemplo, "R", definida pela fórmula do coeficiente angular $(\mathrm{m})$, ou tangente da reta. Depende do seu $(\mathrm{m})$, classifica sua inclinação.

O carro chassi percorreu o plano cartesiano e parou no $1^{\circ}$ quadrante no ponto $A(3,4)$ já no $4^{\circ}$ quadrante teve as coordenadas de $B(-3,-2)$, sendo seu $(m)$ com o valor de $M=(1)$ pelo cálculo do ponto médio feito da razão: $M=3-(-$ 3) / 4 - (-2), onde os $x$ e y são as coordenadas dos pontos $A$ e B. Portanto a inclinação da reta $R$ do carrinho é considerada crescente, pois teve valor de $M=1$. Crescente porque seu resultado é positivo, decrescente resultado seria negativo, constante não varia o valor da inclinação e inexistente se a reta tivesse valor igual a 0 (RAMOS, 2016).

A distância entre dois pontos, dados os pontos pela rota do carro chassi no Plano Cartesiano, onde suas coordenadas são: $A(3,4)$ e $B(0,0)$.

Para calcular a distância entre esses pontos com o nome de $A$ e $B$, usa a fórmula de distância que é: $d^{2}=(x A-$ $x B)^{2}+(y A-y B)^{2}$, que se define $d^{2}=(3-0)^{2}+(4-0)^{2}$. Portanto, pelo cálculo chegaria a distância, ( $d=5)$ (Silva, 2016).

O plano de Argand-Gauss, que representa números complexos podendo-se usar imaginários e reais onde os imaginários são o eixo vertical e o eixo dos números reais é o eixo horizontal. Tendo esse plano, pode-se localizar em qual quadrante o ponto pertence.
E aplicando para o carro chassi, sendo: ponto $A=$ $6+8 \mathrm{i}$, onde $A$ é o nome do ponto e o número que não acompanha o (i), seria o número que pertence aos reais. Já o número $8 \mathrm{i}$, acompanha o (i) que pertence aos imaginários. Localizando o ponto correspondente aos seus eixos, localizando-o estaria no $1^{\circ}$ quadrante (RIGONATTO, 2016).

Na figura 1, é apresentado o carro chassi em cima do plano Cartesiano e Argand-Gauss.

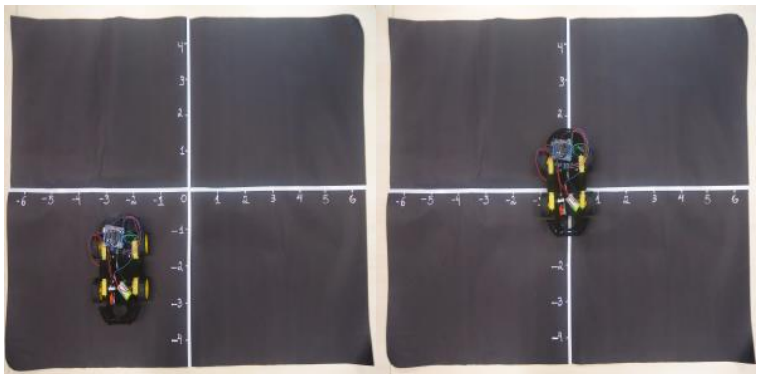

Figura 1: Carro Chassi em cima do plano Cartesiano e Argand-Gauss.

\section{Conclusões}

No mais, a criação do projeto obteve seus resultados esperados, sendo possível ser aplicado seu conteúdo no ensino médio, aos movimentos do carro chassi. Ampliando os estudos elencados, fazendo com que os conceitos sejam entendidos de uma forma mais simples e objetiva.

\section{Agradecimentos}

Agradeço ao IFSP campus Itapetininga e ao CNPq.

MONK, S. Projetos com Arduino e Android: use seu smartphone ou tablet para controlar o Arduino. Porto Alegre: Bookman, 2014. 212 p. (Série Tekne).

RIGONATTO, Marcelo. "Plano de Argand-Gauss"; Brasil Escola Disponível em: http://brasilescola.uol.com.br/matematica/plano-argandgauss.htm. Acesso em: junho, 2016.

Marcos Noé Pedro da Silva. “Distância entre dois pontos”.Mundo Educação. Disponível em http://mundoeducacao.bol.uol.com.br/matematica/distancia-entre-doispontos.htm. Acesso em: junho, 2016.

Danielle De Miranda. "Inclinação da reta e o seu coeficiente angular", Brasil Escola. Disponível em http://brasilescola.uol.com.br/matematica/inclinacao-reta-seu-coeficienteangular.htm. Acesso em: junho, 2016 